\title{
QUALIDADE DE SEMENTES DE MILHETO PARA A COMERCIALIZAÇÃO NO ESTADO DE SANTA CATARINA
}

Jerffeson Araujo Cavalcante ${ }^{1}$, Ricardo Miotto Ternus ${ }^{2}$

${ }^{1}$ Universidade Federal de Pelotas - UFPel, Programa de Pós Graduação em Ciência e Tecnologia de Sementes, Pelotas, RS. ${ }^{2}$ Companhia Integrada de Desenvolvimento Agrícola de Santa Catarina - CIDASC, Florianópolis, SC. Email: jerffeson agronomo@hotmail.com

\section{RESUMO}

O milheto é uma das principais gramíneas utilizadas para cultivo estival, contudo, um dos problemas que envolvem a formação de pastagens no Brasil é a variação apresentada na qualidade das sementes de espécies forrageiras disponíveis no comércio, e isso tem comprometido o estabelecimento das pastagens. Assim, objetivou-se avaliar as características físicas e fisiológicas das sementes de milheto coletadas em estabelecimentos comerciais de diferentes regiões do Estado do Santa Catarina, na safra 2014/2015. Foram utilizados 17 lotes de sementes de milheto, da cultivar BRS 1501, oriundos de diferentes estabelecimentos comerciais e regiões (Extremo-Oeste, Oeste, Meio-Oeste, Norte e Sul) do Estado de Santa Catarina. Avaliouse a qualidade física e fisiológica dos lotes de sementes. A germinação dos lotes analisados, independentemente da região, apresentou-se em conformidade com os padrões legais vigentes. Somente os lotes da região Oeste apresentaram valores inferiores ao padrão legal de 95\% para pureza física, porém, não diferindo dos demais. Não foram verificadas diferenças entre os lotes coletados por região para as avaliações de vigor. Contudo, constata-se que os lotes apresentaram alta germinação e baixa emergência, sendo caracterizado como futuro problema no estabelecimento de pastagens no campo.

Palavras-chave: Pennisetum glaucum L.; controle de qualidade; comercialização.

\section{PHYSICAL AND PHYSIOLOGICAL QUALITY: TRADE OF MILLET SEEDS IN THE STATE OF SANTA CATARINA}

\begin{abstract}
Millet is one of the main grasses used for summer cultivation, however, one of the problems involving pasture formation in Brazil is the variation in the quality of the seeds of commercial forage species, and this has compromised the establishment of pastures. The objective of this study was to evaluate the physical and physiological characteristics of millet seeds commercialized in different regions of the State of Santa Catarina, in the 2014/2015 harvest. Seventeen lots of millet seeds of BRS 1501 from different commercial establishments and regions (Far West, West, Midwest, North and South) of the State of Santa Catarina were used. The physical and physiological quality of seed lots was evaluated. The germination of the analyzed lots, independently of the region, was in accordance with the current legal standards. Only the lots from the West region presented values below the legal standard of $95 \%$ for physical purity, but not differing from the others. No differences between the lots collected by region were verified for the vigor evaluations. However, it was observed that the lots presented high germination and low emergence, being characterized a problem in the establishment of pastures in the field.

Key words: Pennisetum glaucum L.; quality control; trade.
\end{abstract}




\section{INTRODUÇÃO}

O milheto (Pennisetum glaucum L.) é uma gramínea recomendada para cultivo estival, de ciclo curto, crescimento rápido, com boa capacidade de rebrota e alto valor nutritivo, além de boa tolerância a estresses hídricos, o que permite seu cultivo em épocas de menor precipitação (GUIMARÃES JÚNIOR et al., 2009). Devido a estas características, a espécie tem-se apresentado como a gramínea anual de maior importância na formação de pastagens de verão no Estado de Santa Catarina.

A cultura tem ampla aplicabilidade, sendo utilizada como forragem de alto valor nutritivo, no cultivo de grãos e como pastagem (BUSO et al., 2014). Como planta de cobertura de solo, segundo Suzuki e Alves, (2006), o milheto alcançou produção de massa seca de $11,83 \mathrm{t} \mathrm{ha}^{-1}$ e massa verde de $48,54 \mathrm{t} \mathrm{ha}^{-1}$, em sucessão de culturas. Quando é cultivado para produção de grãos ou sementes, além da forragem anterior à colheita, a palhada residual da lavoura também pode ser utilizada para a alimentação dos animais, apresentando assim, altos rendimentos de grãos e de matéria seca por hectare com considerável valor alimentar (JORNADA, 2005).

A forragem dessa gramínea é bem aceita pelos animais, com digestibilidade variando de $75 \%$ em folhas novas a $61 \%$ em folhas velhas, apresentando elevados índices de eficiência de conversão de forragem em produto animal (SKERMAN; RIVEROS, 1990).

Entretanto, um dos problemas que envolvem a formação de pastagens no Brasil é a variação apresentada na qualidade das sementes de espécies forrageiras disponíveis no comércio, a oferta irregular de sementes básicas resultando na comercialização de sementes de baixa qualidade física, fisiológica, genética e sanitária (HOLBIG, 2011).

Segundo Ternus et al. (2016), o sucesso de qualquer empreendimento agrícola baseado na exploração comercial de cultivos vegetais requer a utilização de sementes de alta qualidade, com potencial para produzir plantas vigorosas e produtivas, de maneira uniforme e no menor tempo possível.

Por outro lado, é constante a necessidade da fiscalização do comércio de sementes, que além de verificar a documentação, analisa a qualidade da semente por meio da coleta oficial de amostra. Este procedimento torna-se necessário para constatar se as informações descritas na embalagem estão em conformidade com os padrões mínimos relativos a qualidade física (ausência de outras espécies de plantas cultivadas, de sementes de plantas daninhas, além de não apresentar sementes deterioradas ou danificadas) e fisiológica, (BRASIL, 2009).

Com base no exposto, objetivou-se avaliar as características físicas e fisiológicas de lotes de sementes de milheto postas para comercialização em diferentes regiões do Estado do Santa Catarina, na safra 2014/2015.

\section{MATERIAL E MÉTODOS}

O trabalho foi conduzido no Laboratório Didático de Análise de Sementes do Departamento de Fitotecnia, pertencente a Faculdade de Agronomia Eliseu Maciel da Universidade Federal de Pelotas, Campus Capão do Leão, RS.

Foram utilizados 17 lotes de sementes de milheto, da cultivar BRS 1501, oriundos de diferentes estabelecimentos comerciais e regiões (Extremo-Oeste, Oeste, Meio-Oeste, Norte e Sul) do Estado de Santa Catarina, sendo que cada lote de semente foi obtido a partir do excedente de coleta oficial de amostra de sementes, realizada por Fiscal Estadual Agropecuário (FEA) na safra 2014/2015. Em cada região coletou-se quatro lotes de sementes da categoria S2, exceto para região Sul, com apenas um lote coletado. Portanto, a partir do preparo da amostra média e duplicata, destinou-se uma quantidade de sementes, conforme previsto nas Regras para Análise de Sementes (RAS) para avaliar qualidade física e fisiológica, a partir dos seguintes testes:

Pureza física (PF): realizada segundo as Regras para Análise de Sementes (BRASIL, 2009), sendo os resultados expressos em porcentagem de sementes puras.

Peso de mil sementes (PMS): Foram utilizadas oito subamostras de 100 sementes para cada repetição, provenientes da porção semente pura de cada lote. As sementes foram contadas manualmente e em seguida pesadas em balança analítica com precisão de $0,0001 \mathrm{~g}$ (BRASIL, 2009). Os resultados foram expressos em gramas.

Teste de germinação (GER): foi conduzido com três repetições, sedo cada repetição contendo quatro subamostras de 50 sementes, utilizando-se como substrato rolo de papel para germinação (germitest ${ }^{\circledR}$ ), umedecido com 2,5 vezes o seu peso com água destilada (BRASIL, 2009). As avaliações das plântulas normais foram 
realizadas aos sete dias após a semeadura (DAS) e os resultados expressos em porcentagem de germinação.

Primeira contagem da germinação (PCG): foi realizada aos três dias a partir da semeadura, sendo conduzido juntamente com o teste de germinação sendo os resultados expressos em porcentagem de plântulas normais (BRASIL, 2009).

Comprimento da parte aérea (CPA), da raiz (CR) e total de plântula (CTP): para a determinação do comprimento, 20 sementes foram distribuídas em duas linhas (10 sementes por linha), dispostas no terço superior de duas folhas de papel germitest $^{\circledR}$, previamente umedecidas com água destilada em volume equivalente a 2,5 vezes $o$ seu peso seco (NAKAGAWA, 1999). Posteriormente, foram confeccionados rolos sendo os mesmos acondicionados em germinadores com temperatura de $25{ }^{\circ} \mathrm{C}$. Após três dias, 10 plântulas foram selecionadas ao acaso de cada subamostra das três repetições. A medição do comprimento da parte aérea e das raízes foi obtida com auxílio de um paquímetro de precisão. Já o comprimento total foi obtido pela soma entre a o comprimento parte aérea e da raiz, sendo os resultados expressos em $\mathrm{mm}$.

Massa seca da parte aérea (MSPA) e da raiz (MSR): foi obtida na primeira contagem de germinação, pela média de 10 plântulas coletadas ao acaso para as medidas de comprimento. A determinação da massa seca das plântulas foi obtida gravimetricamente em estufa a $70 \pm 1^{\circ} \mathrm{C}$ até massa constante, sendo os resultados expressos em mg plântula ${ }^{-1}$.

$O$ delineamento experimental adotado foi o inteiramente casualizado (DIC) com três repetições. Após tabulação dos dados, foram verificadas as pressuposições da análise da variância (ANOVA), e sendo estas contempladas, procedeu-se a análise de variância. Quando significativos pelo teste $F$, os dados foram submetidos ao teste de Tukey a $5 \%(p \leq 0,05)$ de probabilidade.

\section{RESULTADOS E DISCUSSÃO}

Observou-se na Tabela 1 que não ouve diferença significativa entre as sementes de milheto coletadas nas diferentes regiões do Estado de Santa Catarina (Extremo Oeste, Oeste, Meio Oeste, Norte e Sul) para as variáveis pureza física, germinação, primeira contagem de germinação, emergência a campo, comprimento da parte aérea, comprimento da raiz, comprimento total de plântula, massa seca da parte aérea e massa seca de raízes.

Quanto ao teste de germinação (Tabela 1), observou-se que os lotes de sementes, em média, apresentaram-se dentro do padrão legal de germinação estabelecida pela Instrução Normativa $\mathrm{N}^{\circ} 30$ de 21 de maio de 2008, que é de $75 \%$ (BRASIL, 2008), porém, quando foi avaliado o teste de emergência em campo, constatou-se que as sementes de milheto apresentaram baixo vigor, no entanto, o teste de primeira contagem mostrou valores bem acima do resultados mensurados pela emergência, sendo que ambos são teste de vigor (Tabela 1). Segundo Lima (2005), é comum encontrar lotes que apresentem valores de germinação semelhantes, mas com diferentes níveis de vigor. Isso ocorre porque as primeiras alterações bioquímicas associadas à deterioração ocorrem antes que se note algum declínio na capacidade germinativa (VIEIRA; KRZYZANOWSKI, 1999).

Considerando que um dos principais requisitos para a comercio de sementes é o teste de germinação, sendo o mesmo como determinante na comercialização junto à pureza, existe uma discrepância entre os valores em que a semente pode oferecer no campo quando relacionado com seu potencial germinativo. De acordo com Menezes et al. (2007) e Lima (2005), o teste de germinação realizado em laboratório, sob condições ideais, nem sempre expressa com precisão a qualidade fisiológica e o vigor dos lotes, pois revela apenas diferenças mais acentuadas entre eles, enquanto testes de vigor, caracterizados por simular condições ambientais que podem variar de ótimas a extremamente adversas, expõe as sementes a condições de estresse, permitindo identificar diferenças menos perceptíveis pelo teste de germinação, estimando o desempenho das sementes no campo.

Portanto, o uso de sementes vigorosas assegura o estabelecimento de uma população adequada de plantas, mesmo sob condições estressantes (FRANÇA NETO et al., 2011). O estabelecimento do estande constitui um dos pilares que sustenta a obtenção de produções elevadas por unidade de área. E neste sentido, não há dúvidas acerca da importância do uso de lotes com potencial fisiológico elevado, entretanto, deve-se ressaltar que vários fatores, como temperatura, umidade e aspectos fitossanitários, além da qualidade das sementes, bem como o manejo na semeadura, afetam a 
produção de uma cultura. Assim, mesmo que a influência do potencial fisiológico se concentre no estabelecimento do estande e desenvolvimento inicial das plantas, isto é uma razão mais que suficiente para justificar a aquisição de lotes de alto vigor (MARCOS FILHO, 2011).

Em relação a massa de mil sementes, diferente do que foi observado para as demais variáveis, na qual constatou-se que os lotes de sementes de milheto coletados na região Oeste e Extremo Oeste apresentaram os menores valores (Tabela 1), diferenciando-se das regiões Sul, Norte e Meio Oeste. Vale destacar que a massa das sementes é influenciada pelas condições climáticas, região geográfica, época de colheita, nutrição das plantas e, principalmente, pelas características genéticas de cada espécie (LAURA et al., 2009).

Dentre os lotes coletados na região do Extremo Oeste e Norte catarinense, observou-se que apenas o lote 3 e lote 4 , respectivamente, apresentaram pureza física abaixo do padrão mínimo para comercialização, mostrando pouca variação entre os lotes coletados nestas regiões (Tabela 2). Já os lotes de sementes de milheto coletados na região Oeste, apresentaram-se, em média, pureza física abaixo do padrão mínimo exigido pelas normas oficiais de comercialização de sementes, estabelecida pela Instrução Normativa $\mathrm{N}^{\circ} 30$ de 21 de maio de 2008 (BRASIL, 2008), com valor de $94 \%$, sendo que o padrão exigido por Lei é de no mínimo 95\%. Resultados similares também foi verificado para os lotes da região Meio Oeste. Destaca-se que com a aplicação dos padrões de tolerância previstos nas regras para análise de sementes (RAS), lotes com pureza física de $94 \%$, no caso da espécie em estudo, são considerados aptos à comercialização (BRASIL, 2009).

Em estudo similar realizado por Olsen et al. (2010), ao realizarem um levantamento da qualidade física e fisiológica de sementes de milheto comercializadas no Estado do Paraná, nas safras 2006, 2007 e 2008, constataram que, dos 28 lotes analisado entre os períodos de 2006 a 2008 , 32\% apresentaram-se inaptos à comercialização devido ao excesso de impurezas.

Para a peso de mil sementes (Tabela 2), observou-se que os lotes de sementes que apresentaram menor pureza física, independente da região, apresentaram o menor peso. Hessel et al. (2012) e Pádua et al. (2010) relatam que menor peso específico geralmente está relacionado com menor viabilidade e vigor das sementes. Lawan et al. (1985) verificaram alto padrão de germinação e aumento na de emergência das plântulas de sorgo e milheto quando foram utilizadas sementes de maior massa especifica.

Com relação à germinação, observou-se que apenas um lote da região Extremo e Meio Oeste e dois lotes da Região Norte apresentaramse inaptos à comercialização, mesmo aplicandose os padrões de tolerância previstos nas RAS (BRASIL, 2009). Por outro lado, os demais lotes, nas regiões analisadas, em média, apresentaram conformidade com os padrões legais para à comercialização, definido pela própria IN 30/2008, como sendo de $75 \%$. Contudo, observou uma ampla variação entre os lotes coletados em todas as regiões, exceto para o Oeste, na qual apresentou pouca variação de germinação entre os lotes de sementes de milheto analisados. Igualmente, ao avaliando os resultados para a porcentagem de germinação, Olsen et al. (2010), concluíram que todos os lotes analisados entre os períodos de 2006 a 2008 apresentou germinação igual ou superior ao padrão mínimo exigido, à época, para o milheto.

Com relação a primeira contagem de germinação, teste que baseia-se no princípio de que as amostras que apresentam maior porcentagem de plântulas normais, na primeira contagem, são as mais vigorosas (BRASIL, 2009), não verificou-se diferenças significativas entres os lotes, independentemente da região. Contudo, Jornada et al. (2005) constataram altercações no vigor das sementes de milheto, avaliadas no teste da primeira contagem de germinação, sendo que o maior vigor foi atribuído ao manejo adotado na produção das sementes, proporcionando maior acúmulo de reservas orgânicas na planta que, posteriormente, foram translocadas as sementes.

Por outro lado, ao avaliar a emergência em campo dos lotes de sementes de milheto (Tabela 2), verificou-se que, mesmo aqueles que apresentaram maior peso de mil sementes, tiveram desempenho insatisfatório quando comparado ao percentual mínimo de emergência esperado à campo. Esta baixa emergência em campo, mesmo em lotes com maior peso de mil sementes, pode estar relacionada a problemas nos procedimentos de colheita, secagem e armazenagem das sementes. Schuch et al. (1999) observaram que o baixo vigor das sementes aumenta o tempo necessário para a protrusão das raízes primárias, em até 2 dias, retardando e reduzindo a emergência, bem como aumentando 
a desuniformidade de emergência. Assim, sementes mais vigorosas podem proporcionar melhores condições intrínsecas para o estabelecimento das plântulas no campo (TERNUS et al., 2017).

Vale ressaltar que o teste padrão de germinação não é suficiente para a identificação precisa de lotes em diferentes níveis de vigor. Deste modo, os testes de vigor tornam-se ferramentas cada vez mais rotineiras pela indústria de sementes para a determinação do potencial fisiológico e, dentre os testes mais utilizados, está o teste de emergência à campo (TERNUS et al., 2016). Porém, Franzin et al. (2004) ratifica que a germinação e a primeira contagem de germinação são testes conduzidos concomitantemente, indicando o desempenho de uma população em condições totalmente favoráveis, sendo, muitas vezes, contraditórios aos resultados de emergência, que são conduzidos em condições de campo.
Quando avaliou-se as sementes dos diferentes lotes de milheto quanto ao crescimento inicial e massa seca (Tabela 2), observou-se que não houve diferença significava entre os mesmos independente da região, exceto para a variável massa seca da parte aérea, na qual os lotes da região Extremo Oeste apresentaram diferentes comportamentos, sendo o lote 1 superior ao lote 3 , os lotes 2 e 4 não diferiram entre si e dos demais. Já no comprimento da parte aérea, constatou-se diferenças entre os lotes nas regiões Oeste e Norte (Tabela 2).

Nakagawa (1999) afirma que as diferenças entre plântulas são, na maioria das vezes, bastante visíveis, todavia há necessidade de valores numéricos para separar aquelas mais vigorosas. Para isso, a determinação do comprimento médio das plântulas normais ou partes destas é realizada, tendo em vista que as amostras que apresentam os maiores valores médios são as mais vigorosas.

Tabela 1. Pureza física (PF), massa de mil sementes (MMS), germinação (GER), primeira contagem de germinação (PCG), emergência a campo (EC), comprimento da parte aérea (CPA), comprimento da raiz (CR), comprimento total de plântula (CTP), massa seca da parte aérea (MSPS) e massa seca da raiz (MSR) de sementes de milheto coletadas em diferentes regiões do Estado de Santa Catarina.

\begin{tabular}{cccccc}
\hline \multirow{2}{*}{ Regiões } & \multicolumn{5}{c}{ Variáveis } \\
\cline { 2 - 6 } & PF (\%) & MMS (g) & GER (\%) & PCG (\%) & EC (\%) \\
\hline Extremo Oeste & $97 \mathrm{a}$ & $5,93 \mathrm{ab}$ & $81 \mathrm{a}$ & $76 \mathrm{a}$ & $41 \mathrm{a}$ \\
Oeste & $94 \mathrm{a}$ & $4,52 \mathrm{~b}$ & $78 \mathrm{a}$ & $71 \mathrm{a}$ & $38 \mathrm{a}$ \\
Meio Oeste & $95 \mathrm{a}$ & $6,32 \mathrm{a}$ & $78 \mathrm{a}$ & $71 \mathrm{a}$ & $34 \mathrm{a}$ \\
Norte & $97 \mathrm{a}$ & $6,41 \mathrm{a}$ & $75 \mathrm{a}$ & $70 \mathrm{a}$ & $40 \mathrm{a}$ \\
Sul & $96 \mathrm{a}$ & $6,39 \mathrm{a}$ & $82 \mathrm{a}$ & $75 \mathrm{a}$ & $32 \mathrm{a}$ \\
\hline CV (\%) & 2,35 & 17,12 & 8,80 & 12,54 & 21,22 \\
\hline Extremo Oeste & $\mathrm{CPA}(\mathrm{mm})$ & $\mathrm{CR}(\mathrm{mm})$ & $\mathrm{CTP}(\mathrm{mm})$ & MSPA (mg) & $\mathrm{MSR}(\mathrm{mg})$ \\
Oeste & $3,58 \mathrm{a}$ & $8,64 \mathrm{a}$ & $12,22 \mathrm{a}$ & $14,50 \mathrm{a}$ & $7,92 \mathrm{a}$ \\
Meio Oeste & $3,56 \mathrm{a}$ & $8,92 \mathrm{a}$ & $12,48 \mathrm{a}$ & $14,89 \mathrm{a}$ & $9,72 \mathrm{a}$ \\
Norte & $3,64 \mathrm{a}$ & $9,15 \mathrm{a}$ & $12,79 \mathrm{a}$ & $13,12 \mathrm{a}$ & $8,60 \mathrm{a}$ \\
Sul & $3,82 \mathrm{a}$ & $8,97 \mathrm{a}$ & $12,79 \mathrm{a}$ & $14,68 \mathrm{a}$ & $8,96 \mathrm{a}$ \\
\hline CV (\%) & $3,43 \mathrm{a}$ & $7,87 \mathrm{a}$ & $11,30 \mathrm{a}$ & $14,10 \mathrm{a}$ & $7,92 \mathrm{a}$ \\
\hline
\end{tabular}

Médias seguidas pela mesma letra minúscula não diferem entre si pelo teste de Tukey a $5 \%(p \leq 0,05)$ de probabilidade erro.

A utilização de sementes de alto valor qualitativo impõe-se como fundamental para a expressão do potencial produtivo da espécie e da variedade em cultivo. A razão, para tanto, é que a semente carrega os avanços do melhoramento vegetal, expresso pelo atributo genético, e tem seu desempenho influenciado por atributos físicos, sanitários e fisiológicos. Entre os atributos da qualidade fisiológica das sementes, o vigor é destacado como relevante por relacionar-se a taxas e uniformidades de germinação, de emergência e de crescimento de plântulas no campo com possibilidades de influenciar também o rendimento em campo (ROSSI et al., 2017).

Assim, torna-se cada vez mais necessária a proposição de regras por parte do setor público, para que os testes de vigor possam ser utilizados como ferramenta do controle externo 
de qualidade, haja vista, as significativas diferenças constatadas entre germinação e vigor verificadas neste estudo que, de maneira direta, impactam sobre a produção e produtividade das pastagens. Além disso, constata-se que os prejuízos advindos do uso de sementes de baixa qualidade se estendem desde o usuário das sementes, onerando o custo de produção, podendo alcançar, inclusive, o consumidor final, que pagará mais caro pelo produto devido ao incremento de custo causado pela qualidade inferior das sementes.

Tabela 2: Pureza física (PF), massa de mil sementes (MMS), germinação (GER), primeira contagem de germinação (PCG), emergência a campo (EC), comprimento da parte aérea (CPA), comprimento da raiz (CR), comprimento total de plântula (CTP), massa seca da parte aérea (MSPS) e massa seca da raiz (MSR) de diferentes lotes de sementes de milheto coletadas em diferentes regiões do Estado de Santa Catarina.

\begin{tabular}{|c|c|c|c|c|c|c|c|c|c|c|}
\hline \multirow[t]{2}{*}{ Lote } & $\begin{array}{l}\text { PF } \\
(\%)\end{array}$ & $\begin{array}{c}\text { MMS } \\
\text { (g) }\end{array}$ & $\begin{array}{l}\text { GER } \\
(\%)\end{array}$ & $\begin{array}{l}\text { PCG } \\
(\%)\end{array}$ & $\begin{array}{l}\text { EC } \\
(\%)\end{array}$ & $\begin{array}{c}\text { CPA } \\
(\mathrm{mm})\end{array}$ & $\begin{array}{c}\mathrm{CR} \\
(\mathrm{mm})\end{array}$ & $\begin{array}{c}\text { CTP } \\
(\mathrm{mm})\end{array}$ & $\begin{array}{c}\text { MSPA } \\
\text { (mg) }\end{array}$ & $\begin{array}{l}\text { MSR } \\
(\mathrm{mg})\end{array}$ \\
\hline & \multicolumn{10}{|c|}{ Extremo Oeste } \\
\hline 1 & $95 \mathrm{~b}$ & $5,21 \mathrm{c}$ & $75 \mathrm{~b}$ & $70 \mathrm{~b}$ & $41 \mathrm{a}$ & $3,97 \mathrm{a}$ & $9,47 \mathrm{a}$ & $13,44 a$ & 19,16 a & $8,73 \mathrm{a}$ \\
\hline 2 & 99 a & $7,29 a$ & $90 \mathrm{a}$ & $88 \mathrm{a}$ & 51 a & $3,67 \mathrm{a}$ & $8,08 \mathrm{a}$ & $11,75 \mathrm{a}$ & $14,00 \mathrm{ab}$ & $9,06 \mathrm{a}$ \\
\hline 3 & $98 \mathrm{a}$ & $6,73 \mathrm{~b}$ & $89 a$ & $87 a$ & $41 \mathrm{a}$ & $3,06 \mathrm{a}$ & $7,79 \mathrm{a}$ & $10,86 a$ & $9,20 \mathrm{~b}$ & $7,43 \mathrm{a}$ \\
\hline 4 & $94 \mathrm{~b}$ & $4,51 \mathrm{~d}$ & $69 \mathrm{~b}$ & $60 \mathrm{c}$ & $33 a$ & $3,62 \mathrm{a}$ & $9,22 \mathrm{a}$ & $12,85 \mathrm{a}$ & $15,66 a b$ & $6,46 \mathrm{a}$ \\
\hline \multirow[t]{2}{*}{ CV (\%) } & 0,66 & 2,95 & 3,50 & 3.62 & 16,43 & 12,01 & 14,89 & 13.30 & 15,11 & 14.05 \\
\hline & \multicolumn{10}{|c|}{ Oeste } \\
\hline 1 & $93 \mathrm{a}$ & $4,30 \mathrm{~b}$ & $79 a$ & $75 a$ & $40 \mathrm{a}$ & $3,20 a b$ & $7,79 \mathrm{a}$ & $10,99 \mathrm{a}$ & $12,56 \mathrm{a}$ & $6,13 \mathrm{a}$ \\
\hline 2 & $95 \mathrm{a}$ & $5,52 \mathrm{a}$ & $78 \mathrm{a}$ & $75 a$ & $38 \mathrm{a}$ & $3,84 a b$ & $9,14 \mathrm{a}$ & $12,98 \mathrm{a}$ & 19,63 a & $11,86 a$ \\
\hline 3 & 93 a & $4,07 \mathrm{~b}$ & $78 a$ & $70 \mathrm{a}$ & $32 \mathrm{a}$ & $4,11 \mathrm{a}$ & $9,90 \mathrm{a}$ & $14,01 \mathrm{a}$ & 14,06 a & $10,03 \mathrm{a}$ \\
\hline 4 & $94 \mathrm{a}$ & $4,20 \mathrm{~b}$ & $77 a$ & $64 \mathrm{a}$ & $41 \mathrm{a}$ & $3,11 \mathrm{~b}$ & $8,84 \mathrm{a}$ & $11,95 a$ & $13,30 \mathrm{a}$ & $10,86 \mathrm{a}$ \\
\hline \multirow[t]{2}{*}{ CV (\%) } & 1,58 & 2,84 & 5,26 & 10,60 & 21,24 & 10,20 & 10,85 & 9,56 & 21,55 & 23,13 \\
\hline & \multicolumn{10}{|c|}{ Meio Oeste } \\
\hline 1 & $95 \mathrm{a}$ & $5,47 c$ & $77 \mathrm{~b}$ & $67 \mathrm{bc}$ & $35 a$ & $3,87 a$ & $9,23 \mathrm{a}$ & $13,10 \mathrm{a}$ & $13,70 \mathrm{a}$ & $9,23 \mathrm{a}$ \\
\hline 2 & $96 \mathrm{a}$ & $7,36 \mathrm{a}$ & $83 a$ & 76 a & $29 a$ & $3,74 \mathrm{a}$ & $10,2 \mathrm{a}$ & $13,95 \mathrm{a}$ & $14,26 \mathrm{a}$ & $5,06 \mathrm{a}$ \\
\hline 3 & $92 \mathrm{~b}$ & $6,54 \mathrm{~b}$ & $70 \mathrm{c}$ & $66 c$ & $33 a$ & $3,67 \mathrm{a}$ & $8,87 \mathrm{a}$ & $12,54 \mathrm{a}$ & 11,83 a & $10,73 \mathrm{a}$ \\
\hline 4 & $94 \mathrm{ab}$ & $5,92 \mathrm{c}$ & $82 \mathrm{a}$ & $75 a b$ & 38 a & $3,28 \mathrm{a}$ & $8,28 \mathrm{a}$ & $11,56 \mathrm{a}$ & $12,70 \mathrm{a}$ & 9,36 a \\
\hline \multirow[t]{2}{*}{ CV (\%) } & 0,87 & 3,20 & 1,99 & 4,80 & 17,09 & 16,58 & 9,14 & 9,78 & 16,26 & 22,40 \\
\hline & \multicolumn{10}{|c|}{ Norte } \\
\hline 1 & $99 \mathrm{a}$ & $4,57 d$ & $77 a b$ & $71 a b$ & $40 a b$ & $3,97 a$ & 9,09 a & $13,06 \mathrm{a}$ & $16,00 \mathrm{a}$ & $8,73 a$ \\
\hline 2 & 99 a & $8,11 \mathrm{a}$ & $84 \mathrm{a}$ & $82 \mathrm{a}$ & $45 a$ & $4,25 \mathrm{a}$ & $9,40 \mathrm{a}$ & $13,65 a$ & 15,36 a & $10,63 \mathrm{a}$ \\
\hline 3 & $95 \mathrm{~b}$ & $6,08 c$ & $70 \mathrm{~b}$ & $65 a b$ & $40 a b$ & $3,01 \mathrm{~b}$ & 8,77 a & $11,79 a$ & $12,23 \mathrm{a}$ & $8,73 \mathrm{a}$ \\
\hline 4 & $93 \mathrm{c}$ & $6,88 \mathrm{~b}$ & $68 \mathrm{~b}$ & $63 \mathrm{~b}$ & $34 \mathrm{~b}$ & $4,02 \mathrm{a}$ & $8,06 \mathrm{a}$ & $12,62 \mathrm{a}$ & $15,13 \mathrm{a}$ & $7,83 \mathrm{a}$ \\
\hline CV (\%) & 0,54 & 1,68 & 5,36 & 9,00 & 9,19 & 7,41 & 7,24 & 5,80 & 19,81 & 22,35 \\
\hline
\end{tabular}

Médias seguidas pela mesma letra minúscula na coluna não diferem entre si pelo teste de Tukey a $5 \%(p \leq 0,05)$ de probabilidade erro.

\section{CONSIDERAÇÕES FINAIS}

A germinação dos lotes analisados, independentemente da região, apresentou em conformidade com os padrões legais vigentes.

Somente os lotes da região Oeste apresentaram valores inferiores ao padrão legal de $95 \%$ para pureza física, porém não diferindo dos demais.

Não foram verificadas diferenças entre os lotes coletados por região para as avaliações de vigor.

\section{AGRADECIMENTOS}

À Companhia Integrada de Desenvolvimento Agrícola de Santa Catarina (CIDASC) pelo apoio na condução e elaboração desta pesquisa.

\section{REFERÊNCIAS BIBLIOGRÁFICAS}

BRASIL. Instrução Normativa no 30, de 21 de maio de 2008. Diário Oficial, Brasília, DF, 2008. 16p. 
BRASIL. Regras para análise de sementes. Ministério da Agricultura e Reforma Agrária. SNDA/DNDV/CLAV, p. 365, 2009.

BUSO, W. H. D.; FRANÇA, A. F. S.; MIYAGI, E. S. Bromatological composition and dry matter digestibility of millet cultivars subjected to nitrogen doses. Arquivo Brasileiro de Medicina Veterinária e Zootecnia, v. 66, n. 3, p. 887-893, 2014. http://dx.doi.org/10.1590/1678-41626746

FRANZIN, S. M.; MENEZES, N. L.; GARCIA, D. C.; WRASSE, C. F. Métodos para avaliação do potencial fisiológico de sementes de alface. Revista Brasileira de Sementes, v. 26, n. 2, p. 6369, 2004. http://dx.doi.org/10.1590/S010131222004000200009.

GUIMARÃES JÚNIOR, R.; GONÇALVES, L. C.; RODRIGUES, J. A. S. Utilização do milheto para produção de silagem. Planaltina: Embrapa Cerrados, 2009. 30p. (Documentos, 259)

HESSEL, C. L. E.; VILLELA, F. A.; AUMONDE, T. Z.; PEDÓ, T. Mesa densimétrica e qualidade fisiológica de sementes de brachiária. Informativo ABRATES, Londrina, v.22, n. 3, p. 7376, 2012.

HOLBIG, L. S.; HARTER, F. S.; GALINA, S.; DEUNER, C.; VILLELA, F. A. Diferenças na qualidade física e fisiológica de sementes de aveia preta e azevém comercializadas em duas regiões do Rio Grande do Sul. Revista da FZVA, v. 18, n. 2, p. 70-80, 2011.

JORNADA, J. B. J.; MEDEIROS, R.B.; PEDROSO, C.E.S.; SAIBRO, J. C.; SILVA, M.A. Efeito da irrigação, épocas de corte da forragem e doses de nitrogênio sobre o rendimento de sementes de milheto. Revista Brasileira de Sementes, v. 27, n. 2, p.50-58, 2005. http://dx.doi.org/10.1590/S0101$\underline{31222005000200008}$

KICHEL, A. N.; MIRANDA, C. H. B. Uso do milheto como planta forrageira. Campo Grande: Embrapa Gado de Corte, 2000, 6p. (Documentos, 49).

LAURA, V. A.; RODRIGUES, A. P. D. C.; ARIAS, E. R. A.; CHERMOUTH, K. S.; ROSSI, T. Qualidade física e fisiológica de sementes de braquiárias comercializadas em Campo Grande - MS. Ciência e Agrotecnologia, v. 33, n. 1, p. 326-332, 2009.
http://dx.doi.org/10.1590/S1413$\underline{70542009000100045}$.

LAWAN, M.; BARNETT, F. L.; KHALEEQ, B.; VANDERLIP, R. L. Seed density and seed size of pearl millet as related to field emergence and several seed and seedling traits. Agronomy Journal, v. 77, n. 4, p. 67-571, 1985. http://dx.doi.org/10.2134/agronj1985.00021962 $\underline{007700040015 x \text {. }}$

LIMA, T. C.; MEDINA, P. F.; FANAN, S. Avaliação do vigor de sementes de trigo pelo teste de envelhecimento acelerado. Revista Brasileira de Sementes, v. 28 n. 1, p. 106-113, 2006. http://dx.doi.org/10.1590/S010131222006000100015.

MARANVILLE, J. W.; CLEGG, M. D. Influence of seed size and density on germination, seedling emergence and yield of grain sorghum. Agronomy Journal, v. 69, n. 2 p. 329-330, 1977. http://dx.doi.org/10.2134/agronj1977.00021962 $\underline{006900020032 x}$.

MARCOS FILHO, J. Testes de VIGOR: dimensão e perspectivas. Seed News, v. 15, n. 1, 2011.

MENEZES, N. L.; GARCIA, D. C.; BAHRY, C. A.; MATTIONI, N. M. Teste de condutividade elétrica em sementes de aveia preta. Revista Brasileira de Sementes, v. 29, n. 2, p. 138-142, 2007. http://dx.doi.org/10.1590/S0101$\underline{31222007000200019}$.

NAKAGAWA, J. Testes de vigor baseados no desempenho das plântulas. In: KRZYZANOSKI, F.C.; VIEIRA, R.D.; FRANÇA NETO, J.B. Vigor de sementes: conceitos e testes. Londrina: ABRATES, 1999. p. 2.1-2.24.

OHLSON, O. C.; SOUZA, C. R.; PANOBIANCO, M. Qualidade física e fisiológica de sementes de capim-colonião e milheto, comercializadas no estado do Paraná. Informativo Abrates, v. 18 , n. 1, p. 30-36, 2010.

PÁDUA, G. P. ZITO, R. K.; ARANTES, N. E.; FRANÇA NETO, J. B. Influência do tamanho da semente na qualidade fisiológica e na produtividade da cultura da soja. Revista Brasileira de Sementes, v.32, n.3, p.09-16, 2010. http://dx.doi.org/10.1590/S0101$\underline{31222010000300001 .}$. 
RANGEL, M. A. S.; MINUZZI, A.; PİEREZAN, L.; TEODÓSIO, T. K. C.; ONO, F. B.; CARDOSO, P. C. Presença e qualidade de sementes esverdeadas de soja na região Sul do Estado do Mato Grosso do Sul. Acta Scientiarum Agronomy, v. 33, n. 1, p. 127-132,

2011. http://dx.doi.org/10.4025/actasciagron.v33i1.485 $\underline{2}$.

ROSSI, R. F.; CAVARIANI, C.; FRANÇA-NETO, J. B. Vigor de sementes, população de plantas e desempenho agronômico de soja. Amazonian Journal of Agricultural and Environmental Sciences, v. 60, n. 3, p. 215-222, 2017. http://dx.doi.org/10.4322/rca.2239.

SCHEFER, S. M.; SAIBRO, J. C.; RIBOLDI, J. Efeito do nitrogênio, métodos de semeadura e regimes de corte no rendimento e qualidade da forragem e da semente de milheto. Pesquisa Agropecuária Brasileira, v. 20, n. 3, p. 309- 317, 1985. http://dx.doi.org/10.1590/S010131222010000300001.

SCHUCH, L. O. B.; NEDEL, J. L.; ASSIS, F. N.; MAIA, M. S. Crescimento em laboratório de plântulas de aveia preta (Avena strigosa Schreb) em função do vigor das sementes. Revista Brasileira de Sementes, v. 21, n. 1, p. 229-234, 1999. http://dx.doi.org/10.17801/01013122/rbs.v21n1p229-234.

SKERMAN, P. J.; RIVEROS, F. Tropical grasses. Rome: Food and Agriculture Organization of the United Nations, 1990. 832p. (FAO- Plant Production and Protection Series; 23)

SUZUKI, L. E. A. S.; ALVES, M. C. Fitomassa de plantas de cobertura em diferentes sucessões de culturas e sistemas de cultivo, v. 65 , n. 1, p. 121127, 2006. http://dx.doi.org/10.1590/S0006$\underline{87052006000100016}$.

TERNUS, R. M.; CAVALCANTE, J. A.; WEISS, A. C.; FOLQUINI, P. S.; BLOEMER, J; MENEGHELLO, G. E. Qualidade de sementes de Lolium multiflorum tetraploide comercializadas em Santa Catarina. Revista Verde de Agroecologia e Desenvolvimento Sustentável, v. 12, n. 1, p.07-11, 2017. http://dx.doi.org/10.18378/rvads.v12i1.4630.

TERNUS, R. M.; MENEGHELLO, G.; BREDA, M. L. E CAVALCANTE, J. A. O controle externo de qualidade na comercialização de sementes. Seed News, v. 20, n. 2, p. 18-23, 2016.

VIEIRA, R.D.; KRZYZANOWSKI, F.C. Teste de condutividade elétrica. In: KRZYZANOWSKI, F.C.; VIEIRA, R.D.; FRANÇA NETO, J.B. (Ed.). Vigor de sementes: conceitos e testes. Brasília: ABRATES, 1999. Cap. 4, p. 1-26.

Recebido para publicação em 14/05/2018 Revisado em 10/07/2018

Aceito em 29/12/2018 